\title{
Original Article UNMET NEED OF POSTPARTUM CONTRACEPTIVES USE IN URBAN SLUMS
}

\author{
Jennyfer Tazneen ${ }^{1}$, Shaheda Hamid ${ }^{2}$, Mostafizur Rahman ${ }^{3}$
}

\begin{abstract}
Background: Unwanted pregnancy is common in slum dwelling couples as they are less aware about postpartum contraceptive. Unmet need of postpartum contraceptive is also evident in slums.

Objective: This study aims to assess the unmet need of post-partum contraceptives used in urban slums.

Materials and Methods: This study was a cross-sectional study on fecund women in postpartum period (0 months to 24 month). A total of 162 postpartum women were face to face interviewed with a pretested semi structured questioner by using software SPSS- 20.

Place and period: The study was conducted in slum area of Jurain and Moghbazar in Dhaka city, during the period of January 2016 to December 2016.

Results: About $51.2 \%$ (83) of the respondents were in the age group of $22-26$ years. Almost $53.1 \%$ (86) of the respondents were illiterate. $57.4 \%$ (93) of the respondents were housewife. $61.1 \%$ of the respondents gave history of monthly family income of 4200-5700 taka. Total unmet need of postpartum contraceptive period, among 162 respondents were 58\% about 94 and met need $42 \%$ (68). Intention for contraceptives used, were 86\% (81) among 94 respondents. Factors related with unmet need - All most $45.7 \%$ of the respondents were not used any contraceptives due to not approved by their husband among 94 respondents. Decision regarding family planning has given by husband $51.85 \%$ (84). There were significant association with education and unmet need of contraceptives use $(\mathrm{p}<0.05)$. Monthly family income was significant association with unmet need of contraceptives use $(\mathrm{p}<0.05)$.

Conclusions: Unmet need for family planning has been a major concern for international population since several decades. Present study indicated a high unmet need for postpartum contraception in the selected area of urban slums in Dhaka city, with a scope to decrease constraints and address user perspective to meet the contraception needs.Change in the attitude of the husband, family and society to accept equity and equality of women and men can positively lead women's unmet need of family planning during postpartum periods.
\end{abstract}

JOPSOM 2019; 38(2): 46-52

Key words: Unmet need, Post-partum contraceptives, Fecund women.

1. Project Coordinator

GFATM TB Control Program

Nari Maitree, Dhaka.

2. Associate Professor

Department of MCH, National Institute of

Preventive and Social Medicine (NIPSOM), Mohakhali, Dhaka-1212.

3. Assistant Professor

Medical College for Women and Hospital, Dhaka.

Correspondence:

Jennyfer Tazneen

Cell phone: +8801552465730

E-mail:anon@bdcom.com

\section{INTRODUCTION}

Unmet need for family planning has been a major concern for international population since several decades. Discounting the partial protection from lactational amenorrhea, unmet need for family planning is particularly high among postpartum women. ${ }^{1}$ Globally, the prevalence of contraceptive use has been increasing, but the unmet need for contraception still remains a problem. More than 215 million women who wish to postpone childbearing in low and middle income countries are not using any form of modern contraception. ${ }^{2}$ Family Planning is considered to be the key in achieving Millennium Development Goals and unmet needs for family planning was added as fifth MDGs in 2006 in the way of tracing improvement in the maternal health. ${ }^{3}$ Postpartum family planning (PPFP) plays a vital role 
in preventing unintended pregnancies and reducing maternal and child mortality. Many factors such as geographical and financial access, provider bias, poor method choice, lower status of women, medico legal restrictions and fear of side effects act as a barrier to family planning use. ${ }^{4}$

Unmet need for family planning in developing country is higher within the extended postpartum period than at other times, perhaps because women are still breastfeeding and the range of methods available after giving birth is limited..$^{5}$ Unintended pregnancies have implications for the health and well-being of women and children, because a woman's risk of death increases with each successive pregnancy. ${ }^{6}$ This study was conducted to assess the unmet need of postpartum contraceptives used in selected urban slums. In Bangladesh unmet need for contraception marginally declined from $16.8 \%$ in 2007 to $12 \%$ according to Bangladesh Demographic Health Survey (BDHS)-2014. MDGs 5 target for unmet need was $7.5 \%$, which is not achieved yet. From a demographic standpoint, reducing unmet need can lower fertility in Bangladesh which is struggling to cope with rapid population growth.

\section{MATERIALS \& METHODS}

This study was a cross-sectional study on fecund women in postpartum period. The study was conducted in slums of Jurain and Moghbazar in Dhaka city. Both areas are under Dhaka south city corporation. It was started in January 2016 and ended in December 2016. People from slums are mostly uneducated and with low income. Participant arePostpartum women ( 0 months to 24 month) lived in the slums of Jurain and Moghbazar in Dhaka city, Willing to participate, At least one living child. Women who were more than 24 months of postpartum period and Severely ill were not included in this study. By purposive sampling, face to face interview and with semi-structured questionnaire was developed initially in English for the collection of data from research participants. The questionnaire was developed using the selected variables according to the specific objectives. The questionnaire contained questions related to Socio-demographic characteristics, Obstetrical characteristics, Intention to use contraceptives, Factors related to unmet need. Sample size was determined statistically through the formula of Daniel. Prevalence of unmet need was needed to calculate the sample size which was $12 \%$ in Bangladesh (BDHS 2014). In this study the following formula of sample size calculation was used $n=z 2 p q / d 2$ and SPSS 20 was used for statistical analysis with $\mathrm{P}$ value less than 0.05 was taken as significant.

\section{RESULTS}

This cross-sectional study was carried out among 162 postpartum women of slum area to assess the unmet need of postpartum contraceptives use in urban slums. About $51.2 \%$ of the respondents were in the age group of $22-26$ years, $27.8 \%$ (45) of the respondents were in the age group of 17-21 yrs and only $1.9 \%$ (03) were age group of 12-16 years. Average age of the respondents was 23.5 years with standard deviation (SD) of \pm 15 years. Minimum age of the respondents was 14 and maximum age was 35 years [table 1]. About 61.1\% (99) of the respondents gave history of monthly family income of 4200-5700 taka, $17.9 \%$ (29) of them had family income between 5800-7300 taka and 4.9\% (08) had family income $>7300$ taka. Average monthly income was 5083 taka with standard deviation (SD) of \pm 6739 taka. Minimum monthly income was 1000 taka and maximum 8000 taka [table 1].

Table 1: Socio-demographic characteristics of the respondents

\begin{tabular}{ccccc}
\hline Age (years) & Frequency & Percentage & Mean & SD \\
\hline $12-16$ & 3 & 1.9 & & \\
$17-21$ & 45 & 27.8 & & \\
$22-26$ & 83 & 51.2 & 23.5 & \pm 15 \\
$27-31$ & 28 & 17.3 & & \\
$32-35$ & 3 & 2.0 & & \\
\hline
\end{tabular}




\begin{tabular}{|c|c|c|c|c|}
\hline \multicolumn{5}{|c|}{ Monthly income (Taka) } \\
\hline $1000-2500$ & 5 & 3.1 & \multirow{5}{*}{5083} & \multirow{5}{*}{ \pm 6739} \\
\hline $2600-4100$ & 21 & 13 & & \\
\hline $4200-5700$ & 99 & 61.1 & & \\
\hline $5800-7300$ & 29 & 17.9 & & \\
\hline $7400-8900$ & 8 & 4.9 & & \\
\hline \multicolumn{5}{|c|}{ Educational status } \\
\hline Illiterate & 86 & 53.1 & & \\
\hline $\begin{array}{l}\text { Able to put } \\
\text { signature }\end{array}$ & 49 & 30.2 & & \\
\hline Primary & 24 & 14.8 & & \\
\hline & 3 & 1.9 & & \\
\hline \multicolumn{5}{|c|}{ Occupational status } \\
\hline Housewife & 93 & 57.4 & & \\
\hline Day labour & 17 & 10.5 & & \\
\hline Service & 27 & 16.7 & & \\
\hline Others & 25 & 15.4 & & \\
\hline Total & 162 & 100 & & \\
\hline
\end{tabular}

Almost $53.1 \%$ (86) of respondents were illiterate, $30.2 \%$ (49) of respondents were able to put signature and only $1.9 \%(03)$ passed secondary school examination. Among 162 respondents 57.4\% (93) were housewife, $16.7 \%$ (27) were in service (housemaid, garments) and 15.4\% (25) were involved in others (swiper, vegetable sealer) [table 1]. The decision regarding the use of contraceptives methods were given by husband $51.85 \%$ (84), both husband and wife were $30.25 \%$ (49), only $12.98 \%$ (21) were taken by respondent $4.94 \%$ (08) were given by others (mother-in-law, FPW) [fig 1].

Figure 1: Distribution of the respondents by decision regarding family planning

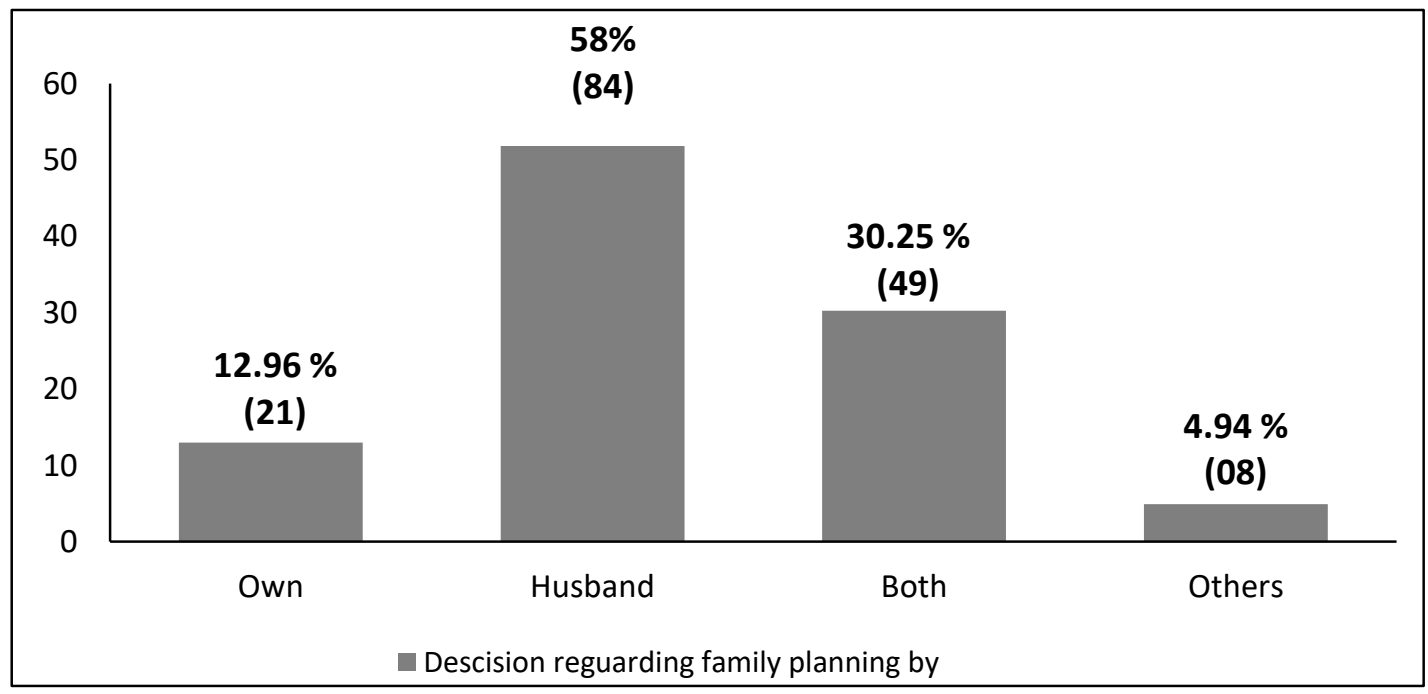


Total unmet need in postpartum contraception used among 162 respondents were $58 \%$ about 94 (proportion of not using any contraceptives during postpartum period) [fig 2].

Figure 2: Proportion of contraceptives use among respondents.

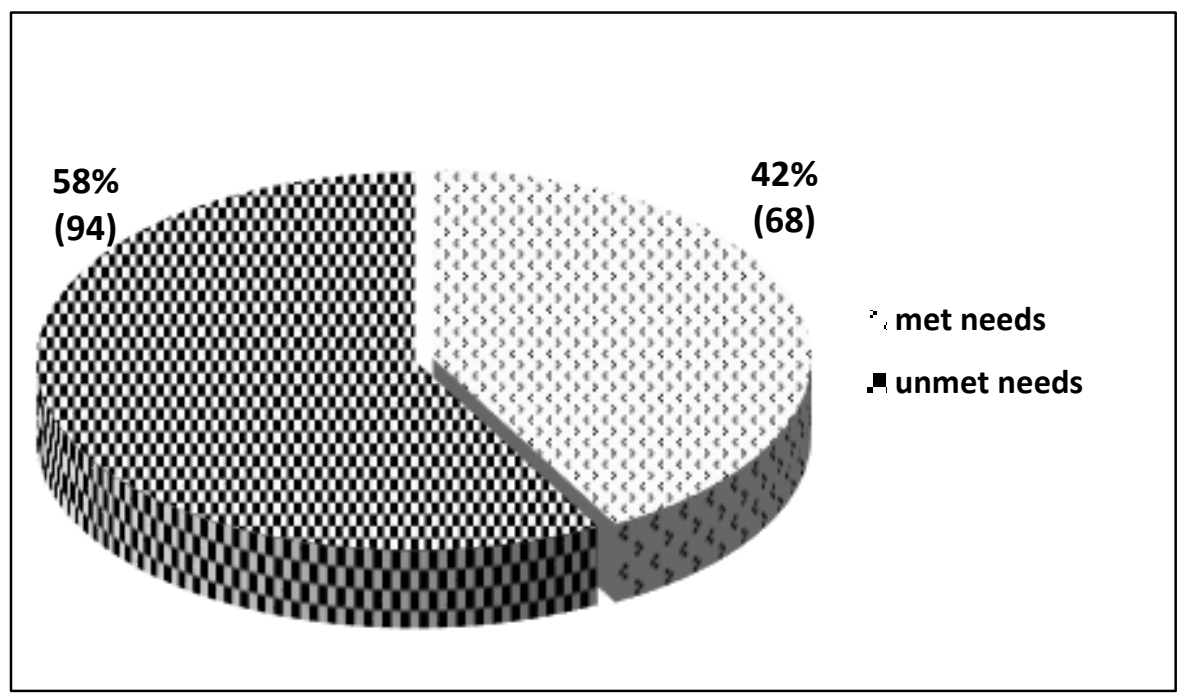

Intention for contraceptives used were $86 \%$ about 81 among 94 respondents, who were not using any contraceptives and no intention were 14\% (13) [fig3].

Figure 3: Distribution of intentions to use of contraceptives

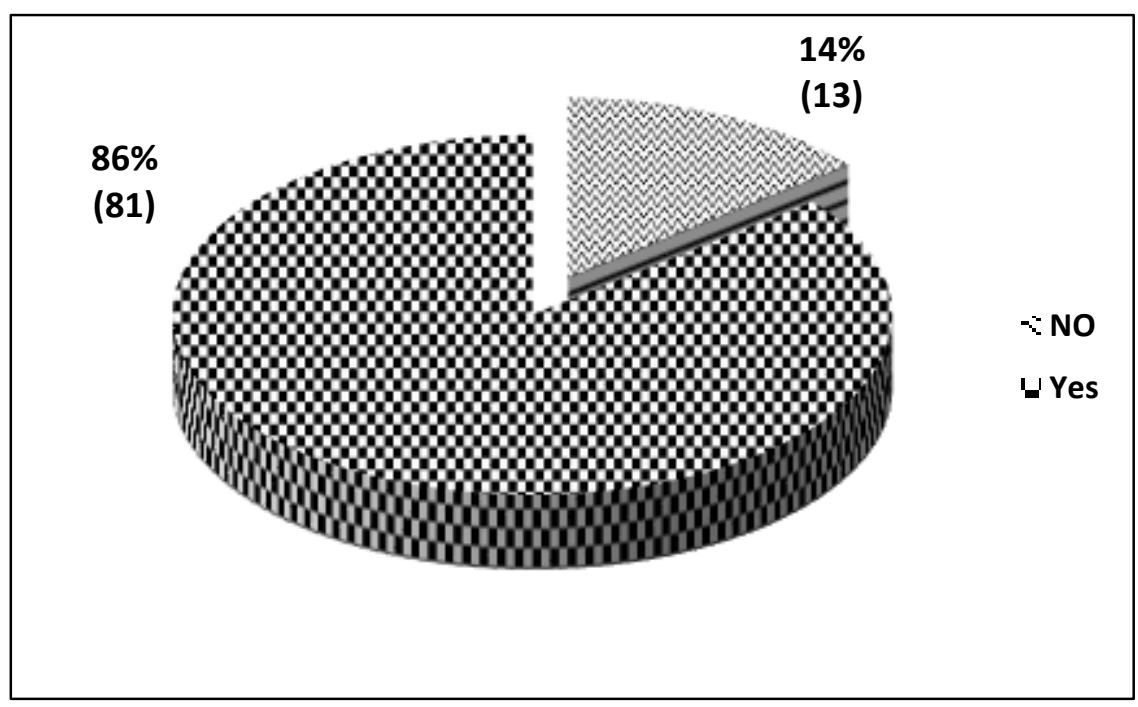

The proportion of the respondents used contraceptives during postpartum period were only $42 \%$ (68). Education of the respondents were significant association with proportion of contraceptives used $(\mathrm{p}<0.05)$. 
Respondents who are illiterate among them $66.3 \%$ were not used any contraceptives-unmet needs and who were literate among them $51.3 \%$ were used contraceptives-met needs [table 2].

Table 2: Association of education and monthly family income with unmet need of contraceptives use by the respondents

\begin{tabular}{|c|c|c|c|c|c|}
\hline \multirow{2}{*}{$\begin{array}{l}\text { Monthly family } \\
\text { income of the } \\
\text { respondents }\end{array}$} & \multicolumn{2}{|c|}{$\begin{array}{c}\text { Unmet need of } \\
\text { contraceptives use }\end{array}$} & \multirow[t]{2}{*}{ Total } & \multirow{2}{*}{$\begin{array}{c}\text { Chi square } \\
\qquad \chi^{2}\end{array}$} & \multirow[t]{2}{*}{ P-value } \\
\hline & Met need & Unmet need & & & \\
\hline $\begin{array}{c}\text { Lower } \\
(1000-4000) \mathrm{tk}\end{array}$ & $\begin{array}{c}26 \\
30.2 \%\end{array}$ & $\begin{array}{c}60 \\
69.8 \%\end{array}$ & 86 & \multirow{2}{*}{10.378} & \multirow{2}{*}{0.001} \\
\hline $\begin{array}{c}\text { Higher } \\
(4001-8000) \text { tk }\end{array}$ & $\begin{array}{c}42 \\
55.3 \%\end{array}$ & $\begin{array}{c}34 \\
44.7 \%\end{array}$ & 76 & & \\
\hline \multicolumn{6}{|c|}{ Education of the respondents } \\
\hline Illiterate & $\begin{array}{c}29 \\
33.7 \%\end{array}$ & $\begin{array}{c}57 \\
66.3 \%\end{array}$ & 86 & \multirow{3}{*}{5.128} & \multirow{3}{*}{0.02} \\
\hline Literate & $\begin{array}{c}39 \\
51.3 \%\end{array}$ & $\begin{array}{c}37 \\
48.7 \%\end{array}$ & 76 & & \\
\hline Total & $\begin{array}{c}68 \\
42.0 \%\end{array}$ & $\begin{array}{c}94 \\
580 \%\end{array}$ & 162 & & \\
\hline
\end{tabular}

Family income of the respondents were associated with the proportion of contraceptives used $(\mathrm{p}>0.05)$. Among them lower income (1000-4000 taka) were unmet needs about $69.8 \%$ those who were not using any contraceptives. Those had higher income (50008000 taka) were used contraceptives $55.3 \%$, they met needs [table 2]. Among 162 postpartum women of slum area about $51.2 \%$ of the respondents were in the age group of $22-26$ year. $61.1 \%$ (99) of the respondents gave history of monthly family income of 4200-5700 taka. Almost $53.1 \%$ (86) of respondents were illiterate and $57.4 \%$ (93) were housewife. Among 162 respondents decision regarding family planning mostly $51.85 \%$ (84) given by husband and respondents herself only $12.96 \%$ (21). Among 162 respondents about 58\% (94) were not used any contraceptives were under unmet need and $42 \%$ (68) were used contraceptives, met need. Among 94 respondents (those who were under unmet need) almost $86 \%$ had intention to use postpartum contraception and $14 \%$ had no intention.

\section{DISCUSSION}

12 percent of currently married women in Bangladesh have an unmet need for family planning services, 5 percent have need for spacing, and 7 percent have need for limiting births (BDHS 2014). This study revealed that about one third $51.2 \%$ of respondents were age group of 22-26 yrs. and 1.9\% were age group of 12-16 yrs. With mean age $23.5 \mathrm{yrs}$. and SD of \pm 15 yrs. [table women of age less than 20 years, parity of two or less, limited education and those who deliver at home were at highest risk for having unmet need. ${ }^{7}$ About $3.1 \%$ were in range of 1000-2500 taka. Most of the respondents family income in this study were 4200-5700 taka only $4.9 \%$ had income $>7300$ taka [table 1]. Average monthly family income was 4771 taka. Minimum monthly income was 1000 taka and maximum were 8000 taka. There were positive association with monthly family income of the respondents and proportion of contraceptives used among respondents $(\mathrm{p}<0.05)$ [table 2]. Among low income they less used contraceptives and those who more income used contraceptives more. Previous study showed more education and more monthly income increase the positivity of women decision towards family planning. ${ }^{8}$ According to this study $53.1 \%$ of respondents were illiterate, $30.2 \%$ of respondents were able to put signature and only $1.9 \%$ pass S.S.C 
examination [table 1]. This study revealed that positive association $(\mathrm{p}<0.05)$ with education of the respondents and proportion of contraceptives use [table 2]. This study were more similar with other reviewed study. The lower the level of education the higher the likelihood were not using any contraceptives $(p<0.05) .36 \%$ of women with no education had an interval of less than 24months compared to $11 \%$ of those with higher education. ${ }^{9}$ In this study about $57.4 \%$ of the respondents were housewife, $16.7 \%$ were service holder ( house maid, garment's worker, office-maid etc.) about $10.5 \%$ were day labor and $15.4 \%$ were doing other work like-vegetable seller, sweeper, baggers [table 1]. Employed women were more likely to decide individually on family planning use which is not in line with previous studies done in Ethiopia and other developing countries. ${ }^{10}$ To this study we found that decision regarding family planning was given by husband about $51.9 \%$, both husband and wife were about $30.2 \%$ and only $13 \%$ were given by respondents own [figure 1]. In another reviewed studys also confirms that women's decision making power is consistent with in India (68\%), Malawi $(28.75 \%)$ and Pakistan $(28 \%)$ were limited towards family planning related to man. Young women in the age range of 34-44 years were 3.8 times more likely to have a decision-making power on family planning use as compared to older women. Women who had attended primary school and college/university were more likely to have a decision-making power as compared to women unable to read and write. ${ }^{10}$ In this study about $86 \%$ respondents had intention [figure 3] to use contraceptives. In reviewed study, self-approval was strongly associated with the intention to adopt a method, 64\% of women who considered the PPFP acceptable have the intention to adopt it. ${ }^{11}$ Throughout this study revealed that about $58 \%$ of the respondents were not using any contraceptive methods and only $42 \%$ were using contraceptive methods [figure 2]. In reviewed study among those with unmet need $(n=73)$, approximately 50 per cent reported client related factors (lack of knowledge, shyness, etc.) as a cause for unmet need and 37 per cent reported contraception related factors: availability, accessibility, affordability, side effects. ${ }^{12}$

\section{CONCLUSION}

Postpartum family planning can contribute significantly to efforts to meet women's fertility goals, prevent unwanted pregnancies, protect mothers and children any unintended complications. The study shows that the state of unmet need of postpartum family planning of the women was not satisfactory in the rural slums of Bangladesh.
Throughout this study most of the women have intention to use contraceptives but not using any contraceptives methods between two years of postpartum period. More ever, due to patriarchal social structure, son's preference increases the number of children among the families having poor level income. Women among the slum dwellers usually practice family planning method rather than men. The empowerment of women has been reported to be a key to using family planning. By enhancing female education and awareness among men in with women can lead to decreasing unmet need in our country.

\section{REFERENCES}

1. Ross, John A. and William L. Winfrey.(2001). "Contraceptive use, intention to use and unmet need during the extended postpartum period," International Family Planning Perspectives 27(1) : 20-27.

2. Singh, Susheela, Jacqueline E. Darroch, Lori S. Ashford, and Michael Vlassoff. (2009). "Adding it up: The costs and benefits of investing in family planning and maternal and newborn health."New York: Guttmacher Institute and United Nations Population Fund. studies in family planning.

3. Madhuumita Naik, (2014). Unmet need for family planning in Bangladesh. Department of humanties and social science national institute of technology rourkela, Odisha.

4. Mitra, S.N, Ann Larson, Gillian Foo and Shahidul Islam. (1990). Bangladesh Contraceptive Prevalence Survey - 1989. Dhaka: Mitra and Associates.

5. Iiene S. Speizer, Jean Christophe Fotso, Chinelo Okigbo, Cheikh Mbacké Faye, Cheikh Seck. (2011). Use of Postpartum Family Planning in Urban Senegal: The Role of Integrated Services.

6. Joyce N. Mumah, Kazuyo Machiyama, Michael Mutua, Caroline W. Kabiru, and John Cleland. (2015). Contraceptive Adoption, Discontinuation, and Switching among Postpartum Women in Nairobi's Urban Slums.Studies in Family Planning.

7. Omrana Pasha, Shivaprasad S Goudar, Archana Patel, Ana Garces, Fabian Esamai, Elwyn Chomba, Janet L Moore, Bhal chandra S Kod kany, Sarah Saleem, Richard J Derman el al,(2015). Postpartum contraceptive use and unmet need for family planning in five low-income countries.Reproductive health journal -12 (Supp 12): S11

8. Do M, Kurimoto N. (2012)..Women's empowerment and choice of contraceptive methods in selected African countries. Journal on Internal Perspective Sex Reproductive Health.; 38(1): 23-33. 
9. Suresh Mehata, Yuba Raj, Paudel, Ranju Mehta, Maureen Dariang, Pradeep Poudel, and Sarah Barnett.(2014). Unmet Need for Family Planning in Nepal during the First Two Years Postpartum.

10. Abeba Daniel Belay, Zelalem Birhanu Mengesha, Manay Kifle Woldegebriel and Yalemzewod Assefa Gelaw. (2016). Married women's decision making power on family planning use and associated factors, in Mizan-Aman, South Ethiopia: a cross sectional study

11. Sebastian Eliason, Frank Baiden, Gloria Quansah- Asare, Yvonne Graham-Hayfron Derek Bonsu, James Phillips and Kofi Awusabo- Asare, et al. (2013). Factors influencing the intention of women in rural Ghana to adopt postpartum family planning. Reproductive Health journal.

12. Bahiya Sulthana, Hemant Deepak Shewade, Bhuvaneswary Sunderamurthy, Keerthana Manoharan \& Manimozhi Subramanian. (2015). Primary Health Centre Muthialpet, Department of Health \& Family Welfare, Puducherry, India. pp 115118 